\title{
OS DESAFIOS DA OPINIÃO CONSULTIVA ENQUANTO MECANISMO DE COOPERAÇÃO JURISDICIONAL NO MERCOSUL
}

\section{THE CHALLENGES OF CONSULTATIVE OPINION AS A MECHANISM OF JUDICIAL COOPERATION IN MERCOSUR}

\author{
Aline Beltrame de Moura \\ Universidade Federal de Santa Catarina - UFSC - (Florianópolis, SC, Brasil)
}

Recebimento: 2 fev. 2018

Aceitação: 16 mar. 2018

\begin{abstract}
Como citar este artigo / How to cite this article (informe a data atual de acesso / inform the current date of access):
MOURA, Aline Beltrame de. Os desafios da opinião consultiva enquanto mecanismo de cooperação jurisdicional no Mercosul. Revista da Faculdade de Direito UFPR, Curitiba, PR, Brasil, v. 63, n. 1, p. 141-159, abr. 2018. ISSN 22367284. Disponível em: <http://revistas.ufpr.br/direito/article/view/55727>. Acesso em: 30 abr. 2018. DOI: http://dx.doi.org/10.5380/rfdufpr.v63i1.55727.
\end{abstract}

\section{RESUMO}

Harmonizar a interpretação e a aplicação do direito decorrente de um fenômeno de integração regional é o fim último dos mecanismos de cooperação jurisdicional. Neste contexto, a opinião consultiva criada pelo sistema normativo do Mercosul tem a função precípua de conferir segurança jurídica e favorecer a cooperação e o diálogo entre as esferas jurisdicionais nacionais e regional, além de possibilitar o acesso, mesmo que indireto, dos indivíduos ao Tribunal Permanente de Revisão. Ocorre que o caráter intergovernamental do bloco também se reflete na estrutura jurisdicional, prejudicando o ideal de uniformização da interpretação e da aplicação do direito mercosulino ao não prever o caráter vinculante das opiniões consultivas e ao criar mecanismos nacionais demasiadamente burocráticos e complexos para o envio de solicitações por parte dos juízes nacionais. Portanto, as dificuldades de cunho pragmático a fim de conferir plena efetividade à opinião consultiva prevista no Protocolo de Olivos têm sido um dos grandes desafios para a sua plena implementação.

\section{PALAVRAS-CHAVE}

Mercosul. Opinião consultiva. Mecanismos de cooperação jurisdicional.

\begin{abstract}
To harmonize the integration and application of the law resulting from a phenomenon of regional integration is the ultimate objective of jurisdictional mechanisms of cooperation. In this context, the advisory opinion created by the Mercosur's normative system has the basic function of conferring juridical security and favouring the cooperation and dialogue between the regional and national jurisdictions in addition to enabling the access, even if indirectly, of individuals to the Permanent Court of Revision. It occurs that the intergovernmental nature of this trade bloc also reflects onto the jurisdictional structure, undermining the ideal of uniformity in the interpretation and application of Mercosur law by not providing the binding of advisory's opinions and by creating overly complex, bureaucratic national mechanisms to the submission of requests by national judges. Therefore, the
\end{abstract}


programmatic difficulties regarding the full granting and effectiveness to the advisory opinion foreseen in the Olivos Protocol are one of the great challenges for its full implementation.

\section{KEYWORDS}

Mercosur. Advisory opinion. Jurisdictional cooperation mechanisms.

\section{INTRODUÇÃO}

Um sistema jurisdicional ágil, preciso e de fácil acesso para os interessados certamente é um dos principais elementos que determinam o êxito ou o fracasso de um processo de integração regional. Nesse contexto, a natureza e o tipo de interconexão existente entre o direito de matriz regional e os ordenamentos jurídicos nacionais, assim como o consequente diálogo entre a jurisdição regional e aquelas nacionais são importantes fatores para a consolidação do próprio fenômeno de integração.

O objetivo do presente estudo, portanto, é realizar uma análise do sistema de solução de controvérsias atualmente vigente no âmbito do processo de integração do Mercosul; em particular, do mecanismo de cooperação jurisdicional. A partir de um exame detalhado das características, dos procedimentos e da atuação do instrumento da opinião consultiva, objetiva-se verificar em que medida o grau de aprofundamento do fenômeno de integração regional interfere na consolidação do sistema de solução de controvérsias, ao mesmo tempo que se busca identificar os desafios a serem superados a fim de garantir a plena efetividade de tal mecanismo.

Conforme será observado, a interação entre os planos jurisdicionais dos Estados membros e o instituído na esfera regional não é vislumbrada com tanta intensidade no Mercosul, o qual apresenta sérias limitações de ordem jurídica, institucional e instrumental para uma efetiva interpretação e aplicação uniforme do seu direito originário e derivado. Na tentativa de estabelecer uma cooperação jurisdicional entre o tribunal regional mercosulino e os judiciários nacionais, criou-se o mecanismo da opinião consultiva, cujo escopo é a harmonização da interpretação e da aplicação do direito do Mercosul, conferindo segurança jurídica. Porém, esse instrumento obedece à lógica da intergovernabilidade e ainda encontra dificuldades em se consolidar no âmbito da cooperação jurisdicional de modo análogo ao sucesso alcançado pelo seu modelo de inspiração europeu: o reenvio prejudicial. 


\section{O TRIBUNAL PERMANENTE DE REVISÃO ENQUANTO ÓRGÃO ARBITRAL DE SOLUÇÃO DE CONTROVÉRSIAS DO MERCOSUL}

O sistema jurisdicional presente no âmbito do Mercosul encontra respaldo legal no Anexo III do Tratado de Assunção de $1991^{1}$, que estabeleceu uma série de etapas² para a adoção de um “Sistema Permanente de Solução de Controvérsias para o Mercado Comum”. Desde 2004, este sistema é regulamentado pelo Protocolo de Olivos ${ }^{3}$, que derrogou o Protocolo de Brasília de $1991^{4}$. O seu principal objetivo é reforçar o caráter jurisdicional do sistema sem eliminar o papel conferido às negociações diplomáticas no caso de controvérsias que venham a surgir entre os Estados Partes acerca da interpretação, aplicação e inadimplemento das normas do Mercosul. O aspecto mais inovador de Olivos residiu na criação de um Tribunal Permanente de Revisão (TPR) encarregado de julgar, em grau de recurso, as decisões proferidas pelos tribunais arbitrais ad hoc, tornando o procedimento de solução de controvérsias mais complexo em razão da instituição do duplo grau de jurisdição.

O TPR, formalmente em atividade desde 13 de agosto de 2004, favorece uma maior segurança jurídica e, segundo alguns autores, é, talvez, o estágio intermediário para um tribunal dotado de supranacionalidade (AMARAL JÚNIOR, 2013, p. 21), uma vez que é incomum submeter laudos arbitrais à revisão de uma instância superior. Salienta-se que as partes podem acordar expressamente em se submeter diretamente, e em única instância, ao TPR, caso em que este terá as mesmas competências que um tribunal arbitral ad hoc.

Apesar do estabelecimento deste tribunal recursal "permanente", o TPR não tem funcionamento continuado, atuando somente após a instauração do litígio e, de regra, quando solicitado por um Estado Parte. Nota-se, portanto, que o ordenamento jurídico do Mercosul ainda não favorece a constituição de uma corte como aquela vislumbrada no âmbito europeu pelo Tribunal de Justiça da União Europeia. Este é o órgão investido da competência de uniformizar a jurisprudência e aplicar as normas comunitárias, de garantir a tutela dos direitos fundamentais dos cidadãos europeus e do princípio da não discriminação, configurando-se como um dos “motores” indispensáveis à integração (MARQUES, 2003, p. 75).

\footnotetext{
${ }^{1}$ O Tratado, celebrado em 26 de março de 1991 entre Argentina, Brasil, Paraguai e Uruguai, entrou em vigor em 19 de novembro de 1991.

${ }^{2}$ A primeira etapa era de natureza diplomática e não jurídica (período entre a entrada em vigor do Tratado até os 120 dias posteriores); a segunda etapa fundava-se em uma instância institucional (da entrada em vigor da proposta até o fim do período de transição - 31/12/1994); por fim, a terceira etapa é a atual, tendo iniciado em 01/01/1995, e representa a adoção de um sistema definitivo de solução de controvérsias. Ver: BARAZZA; JARDEL, 1998, p. 55-62.

${ }^{3}$ Assinado em 18 de fevereiro de 2002 em Olivos, Província de Buenos Aires, entrou em vigor em $1^{\circ}$ de janeiro de 2004.

${ }^{4}$ Assinado em 17 de dezembro de 1991 em Brasília.
} 
A realidade do Mercosul é certamente muito diversa e ainda não está preparada para um avanço deste gênero. A adoção de uma estrutura orgânica minimalista, baseada no método intergovernamental, potencializa o poder dos governos durante as negociações e evidencia a disfuncionalidade do processo decisório; nesse sentido, todos os organismos criados pelo Tratado de Assunção e instrumentos adicionais, entre os quais o TPR, são de natureza intergovernamental, não existindo uma clara divisão de funções institucionais para a cooperação entre os órgãos do mercado comum (MOURA, 2012, p. 307).

A intergovernabilidade do bloco reflete-se, portanto, na sua estrutura jurisdicional, deixando, para os judiciários nacionais, grande parte da função de aplicar e promover o direito mercosulino, tornando temerosa a uniformização da interpretação do acquis normativo regional.

Ademais, segundo interpretação do citado Anexo III do Tratado de Assunção de 1991, o sistema arbitral definido por Olivos, atualmente em vigor, encontra-se em uma fase "transitória”, pois ainda não foi alcançado o objetivo de consolidação do mercado comum. De fato, trata-se de um sistema válido enquanto perdurar a união aduaneira, e, no momento em que a integração vier a ser concretizada em um mercado comum, o Mercosul deverá reformular a estrutura institucional atual e adotar um novo mecanismo de solução de controvérsias em caráter definitivo. Somente nesta ocasião seria o caso de se pensar na criação de um eventual "tribunal de justiça” inspirado no homônimo europeu.

No tocante à competência contenciosa, o sistema atualmente vigente é dividido em dois âmbitos diferentes de aplicação: conflitos entre Estados Partes e reclamações efetuadas por particulares.

O primeiro caso, previsto pelo artigo $1^{\circ}$ do Protocolo de Olivos, refere-se à interpretação, à aplicação e ao inadimplemento do Tratado de Assunção, do Protocolo de Ouro Preto, dos Acordos assinados no seu âmbito, assim como das Decisões do Conselho Mercado Comum (CMC), das Resoluções do Grupo Mercado Comum (GMC) e das Diretivas da Comissão de Comércio do Mercosul (CCM). A segunda hipótese, disciplinada pelo artigo 39 do mesmo Protocolo, diz respeito às reclamações dos particulares, pessoas físicas ou jurídicas, sobre sanções ou aplicação, por parte de qualquer Estado Parte, de medidas legais ou administrativas de efeito restritivo, discriminatório ou de concorrência desleal, em violação a uma das normas supramencionadas.

$\mathrm{O}$ atual sistema prevê que, quanto às controvérsias entre Estados ${ }^{5}$, deve-se inicialmente tentar resolvê-las por meio de negociações diretas e que somente no caso de fracasso destas tentativas

\footnotetext{
${ }^{5}$ Com relação às controvérsias entre Estados Partes, a doutrina disponível é muito vasta: ACCIOLY, 2004, p. 204-226; FONTOURA, 2007, p. 291-297; LABRANO, 1997.
} 
qualquer uma das partes poderá iniciar de modo direto a arbitragem. Uma alternativa, não obrigatória, seria a submissão da questão ao GMC, o qual é competente para formular recomendações a fim de solucionar a divergência antes que as partes recorram à via arbitral (artigos 4 a 8 do Protocolo). Quando não é possível o acordo por meio de tais mecanismos, inicia-se o procedimento arbitral perante um “Tribunal Ad Hoc”, composto por três árbitros (artigo 10.1). Da decisão emanada nesta instância pode ser interposto recurso de impugnação ao TPR, tribunal composto por três ou cinco árbitros, dependendo do número de Estados envolvidos no litígio (artigos 18.1 e 20). Todavia, após as negociações diretas, as partes podem acordar em submeter a lide diretamente ao TPR e, nessas condições, o laudo arbitral será obrigatório e definido, isto é, não sujeito a recurso, adquirindo força de coisa julgada para as partes (artigo 23).

Com relação aos aspectos do sistema de resolução de controvérsias que envolvem os particulares, é relevante salientar que o acesso, assim como na maioria dos sistemas jurisdicionais orientados pelos princípios de direito internacional público, não é garantido de modo direto e apresenta-se um tanto quanto complexo. O Protocolo de Olivos não introduziu nenhuma novidade a este respeito, permanecendo vigentes as mesmas regras delineadas em 1991.

Dessa forma, o procedimento a ser observado pelo particular é, em síntese, o seguinte: i) apresentação da reclamação à Seção Nacional do GMC do Estado Parte onde o particular tenha a residência habitual ou a sede de seus negócios; ii) admitida a reclamação, a Seção pode estabelecer contatos diretos com a Seção Nacional do Estado Parte ao qual se atribui a violação, com o fim de alcançar uma solução imediata ou encaminhar a reclamação diretamente à análise do GMC; iii) recebida a reclamação, o GMC avalia os argumentos do particular, podendo negar o seu prosseguimento; iv) aceita a reclamação, o GMC deve consultar um grupo de especialistas, que dará oportunidade ao particular reclamante e aos Estados envolvidos na reclamação de serem ouvidos e de apresentarem seus argumentos; v) em caso de procedência, abre-se a possibilidade de o Estado Parte voluntariamente aceitar o parecer, adotando as medidas corretivas ou anulando aquelas questionadas; vi) se o requerimento não prosperar e o Estado não adotar voluntariamente o parecer, o Estado Parte interessado pode recorrer diretamente ao procedimento arbitral; vii) por fim, mesmo que ao final do procedimento o GMC declare a improcedência da reclamação, nada impedirá que o Estado Parte reclamante dê início à arbitragem.

Portanto, verificada a admissibilidade da reclamação e o parecer positivo do GMC, não será o particular, mas sim o Estado que terá competência para solicitar a adoção das citadas medidas corretivas ou de nulidade ou, mesmo, iniciar formalmente o procedimento de arbitragem. Neste caso, resta evidente que no Mercosul, diferentemente do que ocorre na União Europeia com o Tribunal de 
Justiça, os particulares não têm “locus standi” para litigar contra os Estados, porque sempre dependerão da decisão de um Estado em assumir a questão litigiosa como se sua fosse e, por consequência, predispor-se em iniciar um litígio com outro Estado Parte (SOARES, 2001, p. 132).

Sob tal perspectiva, “o sistema estabelecido, ao invés de outorgar direitos aos particulares, coloca-os em um total estado de abandono diante da decisão de improcedência da sua reclamação, tendo em vista que esta é irrecorrível” (BERTONI, 2006, p. 68). Esta situação pode ser verificada quando o GMC considera que a reclamação não reúne os requisitos necessários para autorizar o prosseguimento e, nesta hipótese, o GMC é a etapa inicial e a final do procedimento, pois o particular não tem nenhuma opção diante de tal negativa.

Nesse sentido, salienta-se que a mera omissão estatal em razão da não incorporação de norma mercosulina, ocasionando a obstrução do gozo de novos direitos, não constitui motivo suficiente para dar ensejo à reclamação de um particular. Exige-se que este demonstre, de maneira cabal, que o Estado denunciado, em decorrência da omissão, adotou medidas contrárias ao direito do Mercosul e, em razão disso, tenha causado prejuízo ou, ainda, gerado uma real ameaça de violação dos seus direitos (FRANCA FILHO, 2008, p. 366). Por outro lado, o Estado não está condicionado à demonstração de prejuízo, bastando a alegação de violação de alguma norma regional por parte de outro Estado membro, incluindo aí a própria não incorporação como uma espécie de violação (VASCONCELOS, 2016, p. 120).

No âmbito dos processos de integração, a efetividade e a plena vigência do ordenamento jurídico não são garantidas apenas com a existência de órgãos encarregados de assegurar que os indivíduos possam gozar dos direitos provenientes do bloco, mas também com o reconhecimento de que as violações a esses direitos, cometidas pelos Estados por meio de suas ações ou omissões, quando causarem prejuízos aos indivíduos, sejam devidamente reparadas. Neste contexto, fica mais clara a ideia de que os destinatários diretos das normas de qualquer processo integracionista não são os Estados ou seus órgãos, mas seus cidadãos. E, sob tal perspectiva, “el ciudadano deberá tener en el juez nacional el último garante de sus derechos. No sin fundamentos suele decirse que los jueces internos son también 'jueces de la integración’.” (PEROTTI, 2011, p. 486).

Tais fatores, somados à complexidade do acesso do particular ao sistema de solução de controvérsia do Mercosul, resultam na ideia de que parece ser mais conveniente, na prática, o recurso ao poder judiciário nacional a fim de resolver o conflito, dado que qualquer controvérsia que envolva uma situação sobre a aplicação do direito da integração pode ser apresentada perante os tribunais nacionais, considerando que o acesso à justiça é livre e que estas normas integram o ordenamento jurídico interno depois da devida incorporação (ARAÚJO, 1997, p. 157). Eventual alegação de 
imunidade de jurisdição pelo Estado denunciado acabaria sendo afastada sob a justificativa de garantia do devido cumprimento do direito do Mercosul e, em especial, da proteção aos direitos que este confere aos particulares. A violação do ordenamento regional pela autoridade de um dos Estados membros origina a responsabilidade patrimonial de tal Estado perante o particular que tenha sofrido os respectivos danos, independentemente da instância jurisdicional acionada. O princípio da responsabilidade do Estado, e o consequente dever de reparação dos danos, visam, em última análise, garantir a efetividade do próprio sistema normativo (PEROTTI, 2011, p. 469).

Por consequência, o sistema de solução de controvérsias do Mercosul se enfraquece e perde a oportunidade de se afirmar como um importante instrumento para o desenvolvimento do processo de integração, fato que também é facilmente constatado diante do baixo número de recursos submetidos à apreciação da arbitragem no âmbito do Mercosul. De fato, desde a instituição do sistema em 1991, os Tribunais Arbitrais “Ad Hoc” pronunciaram 12 laudos e o Tribunal Permanente de Revisão, desde o início de seu funcionamento em 2004, foi responsável pela pronúncia de seis laudos. As opiniões consultivas foram apenas três e as resoluções, quatro ${ }^{6}$. Desses laudos, somente dois são oriundos de reclamações de particulares, ambos pessoas jurídicas ${ }^{7}$.

\section{A COOPERAÇÃO JURISDICIONAL ENTRE O TPR E AS INSTÂNCIAS JUDICIÁRIAS DOS ESTADOS MEMBROS: O MECANISMO DA OPINIÃO CONSULTIVA}

Considerando que no Mercosul não existe um verdadeiro tribunal de justiça, os órgãos jurisdicionais nacionais acabam assumindo um importante papel na interpretação e na aplicação do direito mercosulino na ordem jurídica interna. No cumprimento da referida missão, possui papel central a competência consultiva conferida pelo Mercosul ao TPR (GONZÁLEZ; RODRÍGUEZ, 2014, p. 84).

Trata-se de um importante mecanismo que vem ao encontro das reclamações dos particulares que acionam o judiciário nacional em razão do descumprimento de uma norma do Mercosul já incorporada ao ordenamento jurídico interno. Em última análise, é um canal de cooperação entre o TPR e os juízes nacionais, a fim de uniformizar o direito do Mercosul, por meio da elaboração de pareceres pelos árbitros do tribunal regional acerca de questionamentos relativos à vigência, interpretação e aplicação das normas do Mercosul, garantindo previsibilidade e segurança jurídica ${ }^{8}$.

\footnotetext{
${ }^{6}$ Dados disponíveis em: <http://www.tprmercosur.org/>. Acesso em: 15 jun. 2017.

${ }^{7}$ Laudo n. 2 de 27 de setembro de 1999 e Laudo n. 10 de 5 de agosto de 2005.

${ }^{8}$ Nesse sentido, ver a Circular emanada do Tribunal Permanente de Revisão n. 119/2012, de 16 de abril de 2012, sobre a

“Regulamentação das Opiniões Consultivas pelo Supremo Tribunal Federal da República Federativa do Brasil”.
} 
Nas palavras dos próprios árbitros mercosulinos, trata-se de “um mecanismo de cooperação, por meio do qual os órgãos jurisdicionais nacionais podem interatuar com o TPR.”"9

De acordo com o capítulo II do Regulamento do Protocolo de Olivos para solução de controvérsias no Mercosul $^{10}$, as opiniões consultivas são pronunciamentos fundamentados, dotados de caráter não vinculante nem obrigatório, emanados pelo TPR em relação às questões jurídicas que digam respeito às normas do Mercosul e que possuam o objetivo de resguardar sua aplicação uniforme no território dos Estados Partes.

Em síntese, o objetivo deste instrumento é “assegurar a correta interpretação, aplicação e cumprimento dos instrumentos fundamentais do conjunto normativo presente no processo de integração do Mercosul, de modo consistente e sistemático” (KLOR, 2008, p. 46-47). Em última análise, por meio das opiniões consultivas busca-se a democratização do acesso à jurisdição do TPR aos jurisdicionados, de maneira a garantir a efetiva proteção dos direitos fundamentais (GOMES, 2013, p. 133).

Com efeito, na primeira opinião consultiva emanada pelo TPR, em $2007^{11}$, os árbitros aproveitaram para esclarecer algumas questões relativas ao conceito deste novo instrumento que, na realidade, resultaria tecnicamente equivocado. Para os árbitros, se aplicado ao cenário de um sistema de solução de controvérsias pertencente a um processo de integração regional, e especialmente quanto às consultas originadas nos órgãos judiciais nacionais, o conceito de opiniões consultivas resultaria incorreto, pois, na realidade, “trata-se de interpretações prejudiciais ou em todo caso, de consultas prejudiciais”, já que seriam realizadas antes do pronunciamento judicial.

Alguns autores, portanto, denominam esse mecanismo de “reenvio pré-judicial” e acreditam que o mesmo venha a encontrar um lugar de destaque no sistema de solução de controvérsias, fortalecendo a tão criticada proteção aos particulares no âmbito do Mercosul (BAPTISTA; ACCIOLY, 2007, p. 167). No entanto, parte da doutrina sustenta que o Mercosul adotou um regime híbrido ao optar pelo mecanismo da opinião consultiva, pois estão ausentes várias das características distintivas das questões prejudiciais, e que esta constitui uma das maiores carências do sistema de solução de controvérsias (PEROTTI, 2008, p. 67). De fato, no Mercosul as opiniões consultivas não possuem efeito vinculante nem são obrigatórias para o juiz nacional consultante; além disso, o pedido de consulta prejudicial submete-se a um procedimento extremamente burocrático, o qual prevê um

\footnotetext{
${ }^{9}$ Opinião Consultiva n. 01/2008, ponto n. 43.

${ }^{10}$ Dec. CMC n. 37/03, de 16 de dezembro de 2003, Montevidéu, Uruguai.

${ }^{11}$ Opinião Consultiva no 01/2007 do TPR: "Norte S.A. Imp. Exp. c/ Laboratórios Northia Sociedade Anônima, Comercial, Industrial, Financeira, Imobiliária e Agropecuária s/ Indenização de Danos e Prejuízos e Lucro Cessante”.
} 
juízo deliberatório sobre a admissibilidade do pedido e sua pertinência processual que, no caso do Brasil, é realizado pelo Supremo Tribunal Federal, segundo dispõe o art. 354-K do seu Regimento Interno.

Independentemente do debate conceitual e terminológico, mostra-se mais relevante levar em consideração a complexidade e o caráter assistemático do ordenamento normativo mercosulino, assim como as particularidades institucionais e jurídicas próprias do modelo intergovernamental, a fim de que seja possível identificar as dificuldades de se estabelecer um critério comum e uma metodologia idônea para que este instrumento consiga lograr os propósitos a que se destina (KLOR, 2011, p. 103).

Apesar das evidentes dificuldades e do seu caráter facultativo, a opinião consultiva elaborada pelo TPR constitui um importante avanço para o bloco (ARAÚJO; SALLES; ALMEIDA, 2007, p. 170) ${ }^{12}$. Pela primeira vez desde a criação do Mercosul, foi reconhecido protagonismo à justiça nacional, fato que contribui à finalidade inspiradora da regulamentação de um viés consultivo no sistema arbitral (KLOR, 2011, p. 106) com vistas à interpretação uniforme. Diz respeito a uma opinião técnica especializada proveniente do TPR, marcando uma tendência, uma linha de pensamento e de orientação filosófica do tribunal arbitral em relação ao caso concreto, a qual pode incidir na decisão que será tomada pelo juiz nacional (CENTURIÓN, 2017, p. 92).

Tal procedimento foi inicialmente disciplinado pela Dec. n. 37/03 do CMC, responsável pela regulamentação do Protocolo de Olivos ${ }^{13}$. Posteriormente, as Decisões n. 02/07 e n. 15/10 do CMC ${ }^{14}$ vieram a estabelecer outras diretrizes para que os juízes nacionais pudessem endereçar o questionamento acerca de um caso concreto que envolvesse a normativa do Mercosul aos árbitros do TPR. Todavia, coube a cada tribunal superior de justiça dos Estados membros, no âmbito de suas jurisdições, definir os procedimentos internos para a tramitação da solicitação da opinião consultiva ${ }^{15}$.

Segundo interpretação sistemática das normativas do bloco, além dos poderes judiciários nacionais, são igualmente legitimados ativos para solicitar opiniões consultivas todos os Estados Partes do Mercosul e qualquer órgão com capacidade decisória do Mercosul, tais como o Conselho do Mercado Comum (CMC), o Grupo do Mercado Comum (GMC) e a Comissão de Comércio do Mercosul (CCM), bem como o Parlamento do Mercosul. Considerando que o escopo do presente

\footnotetext{
12 Segundo o artigo 3 do Protocolo, "O Conselho do Mercado Comum poderá estabelecer mecanismos relativos à solicitação de opiniões consultivas ao Tribunal Permanente de Revisão definindo seu alcance e seus procedimentos.”

${ }^{13}$ Dec. n. 37/03 do CMC de 15 de dezembro de 2003 em Montevidéu, Uruguai.

${ }^{14}$ Decisão n. 02/07 do CMC de 18 de janeiro de 2007 no Rio de Janeiro, Brasil; Decisão n. 15/10 do CMC de 2 de agosto de 2010 em San Juan, Argentina.

${ }^{15}$ No âmbito das suas respectivas jurisdições, o estabelecimento das regras internas para a solicitação de opiniões consultivas foi cumprido pelo Uruguai em 2007 e pela Argentina e Paraguai em 2008. O Brasil regulamentou o procedimento apenas em 2012. Ver: MARTINS FILHO, 2009, p. 128-129.
} 
trabalho é analisar os mecanismos de cooperação jurisdicional presentes nos sistemas de solução de controvérsias dos processos de integração regional, ater-nos-emos à utilização desta ferramenta por parte dos juízes nacionais e à sua efetividade na interpretação do direito do Mercosul.

No tocante à atuação deste mecanismo no ordenamento brasileiro, salienta-se que o procedimento de regulamentação encontrou grande resistência no Supremo Tribunal Federal em virtude, principalmente, do caráter rígido da Constituição Federal de 1988 e da relação do Brasil com as normas provenientes do Mercosul (CABRAL; CABRAL, 2014, p. 76). Por tais razões, apenas em 2012 o Supremo Tribunal Federal elaborou a Emenda Regimental n. 48, de três de abril, cujo texto acrescentou o inciso VIII ao artigo $7^{\circ}$ do seu Regimento Interno, incluindo entre as competências do Plenário do Tribunal aquela de decidir sobre o encaminhamento de solicitação de opinião consultiva ao TPR, mediante juízo de admissibilidade do pedido.

É aconselhável que a solicitação seja acompanhada de um questionário preciso acerca do que se deseja saber do TPR (PEROTTI, 2008). Essa solicitação deve necessariamente originar-se de processo em curso perante o Poder Judiciário brasileiro e restringe-se exclusivamente à vigência ou interpretação jurídica das normas emanadas no seio do Mercosul, sendo legitimados para requerê-la o juiz da causa ou qualquer das partes; todavia, os magistrados não são obrigados a efetuar a consulta caso entendam ser desnecessária.

Portanto, os casos em tramitação perante instâncias inferiores não permitem ao juízo singular ou ao tribunal realizar diretamente a consulta, uma vez que não estaria satisfeito o critério da legitimidade (MARTINS FILHO, 2009, p. 127), de modo diverso do que ocorre com o reenvio prejudicial europeu, cujos legitimados são os juízes nacionais de qualquer instância, constituindo um reenvio “de juiz para juiz”, mas as partes do pleito também podem solicitá-la (CONDINANZI, 2009, p. 208; TESAURO, 1995, p. 141).

Uma vez preenchidos os requisitos de admissibilidade, isto é, o prévio exame realizado pelo tribunal nacional legitimado, o qual não é obrigado a acolher o pedido, a solicitação será encaminhada ao TPR, com cópia para a Secretaria do Mercosul e para as demais cortes supremas dos Estados Partes do Mercosul. Chegando em Assunção, a solicitação passa por um segundo juízo de admissibilidade, após constituição do TPR e designação do relator.

Do recebimento da solicitação, o TPR dispõe do prazo de 65 dias para emitir um pronunciamento fundamentado em normativa Mercosul e tomado pela maioria dos árbitros ${ }^{16}$. Diversamente do que ocorre em todas as atuações do Tribunal, em matéria de opinião consultiva

\footnotetext{
${ }^{16}$ Artigo $1^{\circ}$ da Dec. CMC n. 15/10.
} 
existe a possibilidade de votos dissidentes, desde que sejam fundamentados (PEROTTI, 2008, p. 28) ${ }^{17}$. Como já acenado precedentemente, a opinião consultiva emitida pelo TPR não possui caráter vinculante nem obrigatório, ou seja, o juiz da causa não é compelido a seguir a orientação sinalizada pelo Tribunal. De fato, os próprios árbitros mercosulinos já tiveram a oportunidade de se pronunciar sobre o assunto e afirmaram que “as opiniões consultivas são ditames técnico-jurídicos do TPR que carecem de efeito vinculante."18

Por sua vez, é notório que no âmbito europeu a decisão prolatada pelo Tribunal de Justiça da União Europeia a título prejudicial é lei para o caso concreto e o magistrado nacional deve seguir a interpretação e a orientação fornecida pelos seus pares comunitários no tocante não apenas à decisão propriamente dita, mas também à sua fundamentação ${ }^{19}$. Ao declarar um ato inválido, os tribunais dos Estados membros são obrigados a não mais aplicá-lo ${ }^{20}$, garantindo, assim, a aplicação uniforme do direito europeu.

Não se pode olvidar, contudo, que o caráter facultativo e não vinculante é um mero reflexo da natureza intergovernamental do bloco. A ausência de obrigatoriedade é igualmente vislumbrada em outras organizações internacionais de caráter intergovernamental, tais como as Nações Unidas, em que a Carta de São Francisco (artigo 96) e o Estatuto da Corte Internacional de Justiça (artigos 65-68) habilitam que esta seja solicitada a emanar opinião consultiva sobre determinada questão, bem como no sistema da Organização dos Estados Americanos, no qual a Convenção Americana sobre Direitos Humanos estabelece (artigo 64) o mesmo mecanismo em favor da Corte Interamericana (AREVALOS, 2003, p. 53-54). De outra parte, verifica-se a presença do efeito vinculante da opinião do tribunal regional para o juiz nacional consultante em outros processos de integração, tais como União Europeia, Comunidade Andina, Sistema de Integração Centro-Americana e Comunidade do Caribe (PEROTTI, 2008, p. 79-81).

Ademais, tal caráter não deve necessariamente ser visto como uma desvantagem, pois as opiniões do TPR podem convencer por meio de uma interpretação persuasiva (SAMTLEBEN, 2010, p. 304) e, de qualquer modo, sinalizam um significativo avanço ao possibilitar a sua formulação por um órgão especializado na matéria levada ao juízo. De qualquer modo, este é um obstáculo ponderável, que certamente afetará a adoção das opiniões consultivas no interior de cada país

\footnotetext{
${ }^{17}$ Esta é a previsão do artigo 9 da Dec. CMC n. 37/03.

${ }^{18}$ Opinião Consultiva nº 01/2007 do TPR: “Norte S.A. Imp. Exp. c/ Laboratórios Northia Sociedade Anônima, Comercial, Industrial, Financeira, Imobiliária e Agropecuária s/ Indenização de Danos e Prejuízos e Lucro Cessante”.

${ }^{19}$ Acórdãos TJUE de 3 de fevereiro de 1977, C-52/76, Benedetti; de 14 de dezembro de 2000, caso Fazenda Pública e de 16 de março de 1978, C-135/77, Bosch.

${ }^{20}$ Acórdão TJUE de 13 de maio de 1981, C-66/80, International Chemical Corporation.
} 
(AMARAL JÚNIOR, 2013, p. 22).

Com relação aos particulares, apesar de existirem posicionamentos no sentido de que o TPR seria “a única instituição regional que possui, por meio das opiniões consultivas, acesso direto, pleno e regulamentado de indivíduos à organização regional” (VASCONCELOS, 2016, p. 129), ousamos afirmar, após a análise realizada até o momento, que o indivíduo não pode efetivamente solicitar de forma autônoma uma opinião consultiva. Além do fato de o juiz da causa não ser obrigado a atender à solicitação realizada por uma das partes, o acolhimento do pedido também depende, como visto, do juízo de admissibilidade emitido pelo tribunal superior competente, que, por sua vez, pode negar o seu prosseguimento. Assim, da mesma forma que a reclamação do particular ao TPR deve obedecer ao cumprimento de um procedimento bastante burocrático, o acesso deste ao mecanismo da opinião consultiva também é indireto, haja vista a necessidade de um “duplo” juízo de admissibilidade em âmbito nacional - sem considerar a ulterior análise preliminar realizada pelo próprio TPR.

De qualquer modo, uma análise sistemática da Decisão n. 37/2002 do CMC, juntamente com as regulamentações da Argentina ${ }^{21}$, Paraguai ${ }^{22}$ e Uruguai $^{23}$, fornece-nos a conclusão de que apenas o Brasil $^{24}$ atribui legitimidade às partes para requerer uma opinião consultiva, mesmo que de modo indireto, sendo que nos demais Estados membros apenas o juiz da causa pode fazê-lo (NOGUEIRA; PRADO, 2014, p. 39). Portanto, os particulares que estivessem litigando perante a jurisdição brasileira teriam, em tese, maior probabilidade de levar uma questão para análise do TPR, potencializando a utilização do instituto.

O Supremo Tribunal Federal brasileiro já teve oportunidade de se pronunciar sobre pedido de envio de opinião consultiva ao TPR. O feito havia sido distribuído, em 13 de agosto de 2008, na classe de Petição (recebendo a numeração 4.383/PR), de caráter jurisdicional, antes da edição da Emenda Regimental nº 48/2012 ao Regimento Interno do Supremo Tribunal Federal (RISTF). Ocorre que a Corte acabou optando pela formulação não jurisdicional da consulta ao TPR, a qual deveria ser objeto de deliberação em sessão administrativa (art. 354-K do RISTF).

Diante dessa situação, por meio de decisão monocrática de 14 de dezembro de 2012, publicada em quatro de fevereiro de 2013, o Ministro Dias Toffoli julgou extinto o processo, sem julgamento de mérito, sob a fundamentação de que o pedido "não encontra agasalho no campo da

\footnotetext{
${ }^{21}$ Acordão 13/08 da Corte Suprema de Justiça da Nação. Disponível em: <https://goo.gl/QRij3U>. Acesso em: 8 set. 2017.

${ }^{22}$ Acordão 549 da Corte Suprema de Justiça. Disponível em: <https://goo.gl/SB4U3K>. Acesso em: 8 set. 2017.

${ }^{23}$ Circular 86/2007 da Suprema Corte de Justiça. Disponível em: <https://goo.gl/kiWTv1>. Acesso em: 8 set. 2017.

${ }^{24}$ Art. 354-I do Regulamento do STF: “Têm legitimidade para requerer o encaminhamento de solicitação de opinião consultiva ao Tribunal Permanente de Revisão do Mercosul, o juiz da causa ou alguma das partes.”
} 
jurisdicionalidade”. Encaminhados os autos à Presidência do Tribunal, estes foram reautuados como Processo Administrativo em oito de outubro de 2013, mas tendo em vista o decurso de longo tempo desde o ingresso da solicitação, requereu-se que o solicitante (no caso, a Renault do Brasil S/A) se manifestasse sobre o interesse em dar prosseguimento no feito. A empresa acabou requerendo a desistência da ação e os autos foram arquivados, não tendo o Supremo Tribunal Federal analisado o único pedido de opinião consultiva a ele enviado até o presente momento.

\section{AS OPINIÕES CONSULTIVAS EMANADAS PELO TRIBUNAL PERMANENTE DE REVISÃO DO MERCOSUL}

Tendo em vista o pouco tempo de vigência deste instrumento nos Estados membros, verificase que até o momento foram emanadas apenas três opiniões consultivas pelo TPR, das quais duas foram petições encaminhadas pela Suprema Corte de Justiça da República Oriental do Uruguai e uma pela Corte Suprema de Justiça da República do Paraguai.

A primeira opinião consultiva data de $2007^{25}$ e surge no marco de um litígio judicial entre uma empresa argentina e uma empresa paraguaia, no qual esta reclama por uma indenização por perdas e danos, bem como lucros cessantes, na jurisdição de Assunção. Alegando a prevalência do Protocolo de Buenos Aires sobre Jurisdição Internacional em Matéria Contratual de $1994^{26}$, a empresa argentina opôs uma exceção de incompetência sobre a Lei Nacional Paraguaia n. 194/93. O cerne da opinião consultiva submetida à apreciação do TPR era a determinação da prevalência ou não do tratado sobre a lei nacional.

Após a realização de uma análise minuciosa acerca do conceito e da aplicação do mecanismo da opinião consultiva, os árbitros declararam a prevalência das normas do direito da integração, incorporadas ao ordenamento jurídico interno, não somente sobre as leis nacionais, mas também sobre o direito internacional público e privado dos Estados Partes, compreendendo-se aqueles direitos de ordem pública nacional ${ }^{27}$. Assim, o princípio da primazia do direito do Mercosul deriva da sua natureza de norma regional; em outras palavras, da essência e finalidade do próprio sistema instrumentado a partir do Tratado de Assunção (PEROTTI, 2006, p. 23).

\footnotetext{
${ }^{25}$ Opinião Consultiva n. 01/2007, apresentada pela Primeira Instância no Civil e Comercial do Primeiro Turno da jurisdição de Assunção, Paraguai, no expediente denominado "Norte S.A. Imp. Exp. c/ Laboratórios Northia Sociedade Anônima, Comercial, Industrial, Financeira, Imobiliária e Agropecuária s/ Indenização de Danos e Prejuízos e Lucro Cessante”, pronunciada pelo TPR em 3 de abril de 2007.

${ }^{26}$ Dec. CMC n. 01/94, de 5 de agosto de 1994, Buenos Aires, Argentina. É um Protocolo que se aplica à jurisdição contenciosa internacional de contratos de natureza civil celebrados entre particulares, pessoas físicas ou jurídicas com domicílio ou sede social no território de pelo menos um dos Estados Partes do Mercosul.

${ }^{27}$ Opinião Consultiva n. 01/2007 do TPR, p. 6-11.
} 
A segunda opinião consultiva, pronunciada em $2009^{28}$, solicitava a interpretação do TPR quanto à prevalência das normas Mercosul sobre o direito interno do Uruguai em razão do fato de que uma determinada lei nacional havia implementado novamente o tributo "taxa consular” já previsto por normativa Mercosul. Em outras palavras, a questão central era encontrar uma solução jurídica para o caso de as normas adotadas pelos órgãos dos Estados Parte colidirem com a normativa resultante do processo de integração, estabelecendo a compatibilidade ou incompatibilidade entre elas ou mesmo a hierarquia ou primazia de uma normativa sobre outra.

Nesse sentido, os árbitros salientaram que, na atual etapa do processo de integração, o TPR carece de competência para declarar de forma direta a nulidade ou a inaplicabilidade da norma interna no caso de ser declarada a incompatibilidade desta com o direito do Mercosul. Apenas os órgãos estatais seriam competentes para revogar ou modificar a norma interna incompatível, habilitando medidas que poderiam ser adotadas pelos Estados Partes afetados em caso de descumprimento ${ }^{29}$.

Todavia, os árbitros declararam que seria necessária uma análise por parte do órgão jurisdicional nacional, em conformidade com o ordenamento jurídico interno, a fim de que fosse esclarecida a qualificação acerca da natureza do tributo - se taxa ou imposto. Somente após tal averiguação é que o TPR poderia se pronunciar sobre a qualificação do ato normativo interno e a consequente compatibilidade ou não com o ordenamento jurídico do Mercosul.

Versando sobre a mesma questão jurídica, a terceira opinião consultiva, pronunciada no ano de $2010^{30}$, também obteve idêntica resolução, isto é, o TPR declarou-se competente para conhecer do pedido de opinião consultiva, mas somente após a averiguação, por parte do juiz nacional, do caso concreto acerca da qualificação do objeto principal do pedido, isto é, se tratava-se de taxa ou imposto.

Da análise das três opiniões consultivas até o momento pronunciadas pelo TPR, resta evidente a dificuldade de o mecanismo se estabelecer como um eficaz instrumento de cooperação jurisdicional entre as esferas mercosulina e nacional. O que se percebe é que ele ainda padece de estruturas concretas para a sua plena efetivação. Na prática, a opinião consultiva ainda não alcançou os objetivos aos quais teoricamente se propôs, muito em razão da falta de divulgação e conhecimento desta ferramenta por parte dos juristas (GOMES, 2013, p. 134).

\footnotetext{
${ }^{28}$ Opinião Consultiva n. 01/2008, apresentada pela Suprema Corte de Justiça da República Oriental do Uruguai em relação aos autos do Juizado letrado de primeira instância no civil de $1^{\circ}$ turno, no expediente denominado "Sucessão Carlos Schnek e outros c/Ministério de Economia e Finanças e outros. Cobrança de pesos”, pronunciada pelo TPR em 24 de abril de 2009.

${ }^{29}$ Opinião Consultiva n. 01/2008 do TPR, ponto 30.

${ }^{30}$ Opinião consultiva n. 01/2009, apresentada pela Suprema Corte de Justiça da República Oriental do Uruguai a respeito dos autos do processo do Juizado de Primeira Instância da $2^{\text {a }}$ Vara Cível, no expediente denominado "Frigorífico Centenário S.A. c/ Ministério de Economia e Finanças e outros. Cobrança de pesos. IUE: 2-43923/2007”, pronunciada pelo TPR em $1^{\circ}$ de dezembro de 2010.
} 
Assim, em última análise, o magistrado nacional, "diante de conflito entre normas comunitárias e internas, não terá alternativa senão recorrer à Constituição de seu país e à jurisprudência de seus tribunais superiores” (TRINDADE, 2006, p. 51), fazendo uso de instrumentos legais, doutrinários e jurisprudenciais que se encontram ancorados em parâmetros distintos e que levam em consideração as particularidades e peculiaridades de somente um ordenamento jurídico nacional, o qual, frequentemente, prescinde de uma visão regional de integração.

Além da promoção do acesso à informação no meio jurídico, uma outra possível solução a fim de incentivar a utilização da opinião consultiva é a adoção de mecanismos capazes de atribuir valor obrigatório, a todos os Estados Partes, à opinião proferida pelo TPR, bem como estabelecer a incursão de responsabilidade internacional por parte do Estado eventualmente descumpridor (CABRAL; CABRAL, 2014, p. 80-81).

As críticas apresentadas refletem, de certo modo, o atual estágio de desenvolvimento do próprio fenômeno de integração do Mercosul. Vislumbram-se incipientes mecanismos jurídicos de diálogo entre as jurisdições nacionais e a instância arbitral regional, em que o juiz estatal não conta com uma verdadeira estrutura judiciária comunitária que o auxilie na interpretação do direito de matriz regional. Nesse contexto, a necessidade de harmonização do arcabouço jurídico do Mercosul e a proteção dos indivíduos são questões de certo modo “marginalizadas” pelo sistema de solução de controvérsias regional e destinadas aos juízes nacionais (VÉRTIZ; FERNÁNDEZ; PASCUAL, 2012, p. 18). Não podemos esquecer que "las normas de todo proceso de integración - entre ellos el nuestro - tienen un destinatario directo, que no son los Estados o sus órganos, sino sus ciudadanos” (PEROTTI, 2008) e, nesse sentido, o cidadão tem no juiz nacional o efetivo garantidor de seus direitos.

Apesar das dificuldades expostas, não podemos esquecer que a relevância e a contribuição das opiniões consultivas, do modo como foram delineadas pelo Protocolo de Olivos, é promover a segurança jurídica dos processos de integração por meio de uma atuação conjunta dos tribunais nacionais, haja vista que estes são os maiores responsáveis pelo julgamento e aplicação das normas do Mercosul (KLUMPP, 2007, p. 82). Nesse sentido, os magistrados dos Estados membros possuem um grande potencial de participação decisiva na vigência do direito do Mercosul, atuando como verdadeiros agentes do fenômeno de integração regional. 


\section{CONSIDERAÇÕES FINAIS}

O futuro de um processo de integração regional está intimamente ligado ao aspecto jurídico e especialmente às questões jurisdicionais. O sistema de solução de controvérsias no âmbito regional deve se adaptar aos avanços alcançados pelas forças políticas, ao mesmo tempo que facilita o próprio desenvolvimento e aprofundamento do fenômeno integracionista (SAMTLEBEN, 2010, p. 262). Tendo presente tal pressuposto, foi possível observar as particularidades do sistema jurisdicional atualmente vigente no Mercosul. O nível de eficácia alcançado por este sistema é justificável na medida em que resta evidente o grau de desenvolvimento de tal processo de integração tanto do ponto de vista econômico quanto em relação aos aspectos institucional e normativo. Neste contexto, certamente as ferramentas adotadas pelo sistema de solução de controvérsias são coerentes com a realidade na qual se encontra tal fenômeno de integração.

O sistema jurisdicional do Mercosul, baseado na arbitragem e nos princípios de direito internacional clássico, dispõe de uma estrutura institucional e normativa ainda em construção e, por tal razão, pode, em determinadas situações, não oferecer a instrumentalização de mecanismos aptos a tutelar, de modo efetivo, os cidadãos e os próprios Estados membros diante da violação de uma norma do Mercosul. A participação dos indivíduos no sistema jurisdicional mostra-se um dos grandes desafios à plena inserção deles na esfera regional, dado o acesso indireto de que dispõem a fim de encaminhar uma reclamação ou solicitar uma opinião consultiva ao TPR.

Apesar das problemáticas inerentes ao próprio estágio de desenvolvimento do processo de integração, não se pode olvidar que a criação do mecanismo de opinião consultiva se mostra uma relevante tentativa de inserir os magistrados nacionais no debate acerca das questões do Mercosul, incitando-os a participar deste processo como verdadeiros agentes, criando as bases para o estabelecimento de uma efetiva cooperação jurisdicional, como aquela já plenamente vislumbrada no âmbito da União Europeia.

Ocorre que o desconhecimento dos juristas sobre os mecanismos previstos pelos tratados mercosulinos e os próprios direitos ali garantidos é um obstáculo ao processo de integração regional e, em especial, ao tribunal que representa o guardião deste acervo. Resta, portanto, evidente que a práxis ainda não reflete as inovações teóricas delineadas pelo Protocolo de Olivos.

\section{REFERÊNCIAS}

ACCIOLY, Elizabeth. O Atual mecanismo de solução de controvérsias do Mercosul: o Protocolo de Olivos. Revista da Faculdade de Direito, Lisboa, v. 45, n. 13, 2004, p. 204-226. 
AMARAL JÚNIOR, Alberto de. Reflexões sobre a solução de controvérsias do Mercosul. Revista de la Secretaría del Tribunal Permanente de Revisión. Año 1, № 1, 2013, p. 11-26.

ARAÚJO, Nádia de. Mecanismo de Solução de Conflitos. In: A agenda política e institucional do Mercosul: aportes para a integração regional. Fundação Konrad Adenauer, n. 14, 1997.

ARAÚJO, Nádia de; SALLES, Carlos Alberto de; ALMEIDA, Ricardo Ramalho. Medidas de cooperação interjurisdicional no Mercosul. In: BASSO, Maristela (Org.). Mercosul-Mercosur: estudos em homenagem a Fernando Henrique Cardoso. São Paulo: Atlas, 2007, p. 169-204.

AREVALOS, Evelio Fernandez. Opiniones consultivas, medidas provisionales y medidas excepcionales y de urgência. In: Solução de Controvérsias no Mercosul. Brasília: Câmara dos Deputados, Coordenação de Publicações, 2003, p. 51-70.

BAPTISTA, Luiz Olavo; ACCIOLY, Elizabeth. Solução de Divergências no Mercosul. In: BASSO, Maristela (Org.). Mercosul-Mercosur: estudos em homenagem a Fernando Henrique Cardoso. São Paulo: Atlas, 2007.

BARAZZA, Alejandro; JARDEL, Silvia. Mercosur: aspectos juridicos y economicos. Buenos Aires: Ciudad Argentina, 1998.

BERTONI, Liliana. Laudos Arbitrales en el Mercosur. Buenos Aires: Ciudad Argentina, 2006.

CABRAL, Alex Ian Psarski; CABRAL, Cristiane Helena de Paula Lima. Mercosul jurídico: as opiniões consultivas e o princípio constitucional da integração na República Federativa do Brasil. Revista do Instituto do Direito Brasileiro. Ano 3, n. 1, 2014.

CENTURIÓN, Carlos Hugo. Aporte del TPR al proceso de integración-MERCOSUR. Rev. secr. Trib. perm. revis. Año 5, No 9; Marzo 2017; p. 78 - 100.

CONDINANZI, Massimo. Corte di Giustizia e Trattati di Lisbona: innovazioni strutturali ed organizzativi. In: BILANCIA, Paola; D’AMICO, Marilisa (a cura di). La nuova Europa dopo il Trattato di Lisbona. Milano: Giuffrè, 2009.

FONTOURA, Jorge. A revisão institucional do Mercosul: Ouro Preto II. Revista de Estudos Europeus, Coimbra, v. 1, n. 1, jan./jun. 2007, p. 291-297.

FRANCA FILHO, Marcílio Toscano Franca. O silêncio eloquente: omissão do legislador e responsabilidade do Estado na Comunidade Europeia e no Mercosul. Coimbra: Almedina, 2008.

GOMES, Eduardo Biachi. Integração econômica no Mercosul: opiniões consultivas e a democratização no acesso ao tribunal permanente de revisão. Revista de Direito Internacional. Vol. 10, n. 1, 2013.

GONZÁLEZ, Jorge Chediak; RODRÍGUEZ, Pablo Benítez. Acerca de la competencia consultiva del tribunal permamente de revision del mercosur y de la experciencia del poder judicial del Uruguay em la tramitación de opiniones consultivas. RSTPR, Año 2, No 4; agosto 2014; p. 83-91.

KLOR, Adriana Dreyzin de. La primera opinion consultiva em Mercosur: germen de cuestión 
prejudicial? In: ACCIOLY, Elizabeth (Coord.). Direito no século XXI: em homenagem ao professor Werter Faria. Curitiba: Juruá, 2008, p. 41-64.

KLOR, Adriana Dreyzin de. Las opiniones consultivas en Mercosur. In: LAPENTA, Eduardo; RONCHETTI, Alfredo Fernando (Coord.). Derecho y Complejidad: en homenaje al Prof. Dr. Miguel Ángel Ciuro Caldani. Tandil: Universidad Nacional del Centro de la Provincia de Buenos Aires, 2011, p. 99-134.

KLUMPP, Marianne. La efectividad del sistema jurídico del Mercosur. In: BASSO, Maristela (Org.). Mercosul-Mercosur: estudos em homenagem a Fernando Henrique Cardoso. São Paulo: Atlas, 2007, p. 53-96.

LABRANO, Roberto Ruiz Diaz. Hacia un tribunal de carácter supranacional. In: Pérez Gonzáles, Manuel (Org.). Desafíos del Mercosur. Buenos Aires: Ciudad Argentina, 1997.

MARQUES, Claudia Lima. O “direito do Mercosul”: direito oriundo do Mercosul, entre direito internacional clássico e novos caminhos de integração. Revista de Derecho Internacional y del Mercosur. Año 7, n. 1, 2003, p. 61-88.

MARTINS FILHO, Marcos Simões. A legitimidade de o juiz brasileiro solicitar opiniões consultivas. Revista da Seção Judiciária do Rio de Janeiro, n. 25, 2009, p. 177-133.

MOURA, Aline Beltrame de. Organizações internacionais de natureza supranacional e intergovernamental: o caráter híbrido da União Europeia e a intergovernamentabilidade do Mercosul. In: OLIVEIRA, Maria Odete de. Organizações internacionais e seus dilemas formais e informais. Ijuí: Unijuí, 2012.

NOGUEIRA, Cássia Cavalcante de Oliveira; PRADO, Henrique Sartori de Almeida. Revista de la Secretaría del Tribunal Permanente de Revisión. Año 2, № 4, 2014, p. 27-47.

PEROTTI, Alejandro D. ¿Quién paga los costos del incumplimiento de las sentencias del Tribunal Permanente de Revisión (MERCOSUR)? Responsabilidad del Estado por violación del Derecho de la integración. Revista Quaestio Iuris, vol. 04, nº 01, 2011, p. 424-487.

PEROTTI, Alejandro D. Los principios del derecho comunitario y el derecho interno en Europa y la Comunidad Andina, aplicabilidad en el derecho del MERCOSUR. Cordoba: Mediterránea, 2006.

PEROTTI, Alejandro D. Tribunal Permanente de Revisión y Estado de Derecho en el Mercosur. Buenos Aires: Marcial Pons de Argentina, 2008.

SAMTLEBEN, Jürgen. Rechtspraxis und Rechtskultur in Brasilien und Lateinamerika: beiträge aus internationaler und regionaler perspective. Aachen: Shaker Verlag, 2010.

SOARES, Guido Fernando Silva. A Arbitragem e a Conaturalidade com o Comércio Internacional. In: PUCCI, Adriana Noemi (Coord.). Aspectos Atuais da Arbitragem: coletânea de artigos sobre arbitragem. Rio de Janeiro: Forense, 2001.

TESAURO, Giuseppe. Diritto Comunitario. Padova: CEDAM, 1995. 
TRINDADE, Otávio Augusto Drummond Cançado. O Mercosul no direito brasileiro: incorporação de normas e segurança jurídica. Belo Horizonte: Del Rey, 2006.

VASCONCELOS, Raphael Carvalho de. O Mercosul e as linhas gerais de seu sistema de solução de controvérsias. Rev. secr. Trib. perm. revis. Año 4, No 8; agosto 2016, p. 113-135.

VÉRTIZ, Juana Goizueta; FERNÁNDEZ, Itziar Gómez; PASCUAL, María Isabel González (Dir.). La libre círculación de personas en los sistemas de integración económica: modelos comparados: Unión Europea, Mercosur y Comunidad Andina. Navarra: Thomson Reuters Aranzadi, 2012.

Aline Beltrame de Moura Bacharel e Mestre em Direito pela Universidade Federal de Santa Catarina e Doutora em Direito pela Università degli Studi di Milano (Itália). Professora Adjunta I no Curso de Graduação e Professora Permanente no Curso de Pós-Graduação em Direito da Universidade Federal de Santa Catarina (UFSC). Coordenadora do Núcleo de Prática Jurídica do CCJ/UFSC. E-mail: alineb.moura@gmail.com 